\title{
Intersectionality of gender in recruitment and retention of the health workforce in Africa: a rapid review
}

Chigozie Uneke ${ }^{1}$ and Bilikis Uneke ${ }^{1}$

${ }^{1}$ African Institute for Health Policy and Health Systems, Ebonyi State University, Abakaliki, Nigeria (Correspondence to: Chigozie Uneke: unekecj@ yahoo.com).

\begin{abstract}
Background: Despite the importance of gender and intersectionality in policy-making for human resources for health, these issues have not been given adequate consideration in health workforce recruitment and retention in Africa.

Aims: The objective of this review was to show how gender intersects with other sociocultural determinants of health to create different experiences of marginalization and/or privilege in the recruitment and retention of human resources for health in Africa.

Methods: This was rapid review of studies that investigated the intersectionality of gender in relation to recruitment and retention of health workers in Africa. A PubMed search was undertaken in April 2020 to identify eligible studies. Search terms used included: gender, employment, health workers, health workforce, recruitment and retention. Criteria for inclusion of studies were: primary research; related to the role of gender and intersectionality in recruitment and retention of the health workforce; conducted in Africa; quantitative or qualitative study design; and published in English.

Results: Of 193 publications found, nine fulfilled the study inclusion criteria and were selected. Feminization of the nursing and midwifery profession results in difficulties in recruiting and deploying female health workers. Male domination of management positions was reported. Gender power relationship in the recruitment and retention of the health workforce is shaped by marriage and cultural norms. Occupational segregation, sexual harassment and discrimination against female health workers were reported.
\end{abstract}

Conclusion: This review highlights the importance of considering gender analysis in the development of policies and programmes for human resources for health in Africa.

Key words: Gender, health workforce, employment, personnel selection, Africa

Citation: Uneke C; Uneke B. Intersectionality of gender in recruitment and retention of the health workforce in Africa: a rapid review. East Mediterr Health J. 2021;27(7):698-706. https://doi.org/10.26719/2021.27.7.698

Received: 26/04/20; accepted: 11/10/20

Copyright (C) World Health Organization (WHO) 2021. Open Access. Some rights reserved. This work is available under the CC BY-NC-SA 3.0 IGO license (https://creativecommons.org/licenses/by-nc-sa/3.o/igo).

\section{Introduction}

According to the recent world health statistics report (1), Africa is still one of the continents with the highest burden of disease. Most countries in Africa have very weak health systems and poor-quality health care, which, to a large extent, may be attributed to critical shortages in human resources for health (2). In the 2006 world health report, Africa was classified as having the most severe health workforce shortage in the world; of the 57 countries considered to be facing a health workforce crisis (health workforce density ratio lower than 2.3 health workers per 1000 population), 36 were in Africa (3).

The World Health Organization (WHO) noted that efforts in Africa to ensure adequate human resources for health are constrained by inadequate institutional capacity for human resources management, inadequate numbers of health workers, slow progress in educational reforms, skewed distribution of health workers, lack of incentives, ineffective retention strategies for health workers and, most importantly, gender inequality (2). Experts in human resources for health have noted that gender inequality and imbalance are a major challenge to delivery of health care services in low-income settings (4). According to Newman, "gender inequalities are systems inefficiencies that contribute to clogged health worker educational pipelines, recruitment bottlenecks, attrition, and worker maldistribution in formal and non-formal health workforces" (5). It has been argued that the failure in policy and planning for human resources can be traced to health mangers disregard for gender (6).

A recent study in parts of Africa on the gendered health workforce observed that in Africa, difficulties in recruitment are often made more severe because of a history of low, irregular salaries for health professionals, poor staff mix and unbalanced gender mix (7). The study also noted that "retention is also problematic, with internal (across sectors) and external brain-drain as a result of poor and irregular remuneration, poor HR management practices and limited promotion opportunities, alongside poor working conditions, especially in rural areas" (7). In Africa where human resources for health and other health system components are highly influenced by context-specific factors, especially social and cultural determinants of health, gender as a sociocultural factor 
therefore plays a critical role in recruitment and retention of health workers $(2,8,9)$.

Despite the importance of gender and intersectionality in policy-making for human resources for health, these have not been given adequate consideration in matters related to health workforce recruitment and retention in Africa. In this paper, intersectionality is understood as the concept that brings in an additional series of characteristics and contexts that intersect with gender in dynamic ways to disadvantage or privilege different individuals creating inequities (10,11). Bowle, further defined intersectionality as a "theoretical framework that posits that multiple social categories (e.g., race, ethnicity, gender, sexual orientation, socioeconomic status) intersect at the micro level of individual experience to reflect multiple interlocking systems of privilege and oppression at the macro, social-structural level (e.g., racism, sexism, heterosexism)" (12). Although consensus on the concept and definition of intersectionality is lacking, it is increasingly recognized by researchers on human resources for health as an important theoretical approach that provides a framework for understanding inequalities within the health systems and particularly those associated with recruitment and retention of the health workforce by highlighting intersections of individuals' multiple identities within social systems of power that determine the placement and position of health workers $(11,13)$.

Gender is undoubtedly one of the main identities of an individual which influence human resources for health in most low- and middle-income countries. Gender has been described as a social and political construct that is instilled in personal actions and organizational structures, practices and processes such that it affects a person's professional development and career advancement (14). This explains why deeper exploration of gender and intersectionality in human resources for health is gaining momentum worldwide because there are many unanswered questions about the subject. For instance, it is estimated that up to $75 \%$ of health workers are female but this gender ratio is not reflected in certain categories of the health workforce, including the top levels of leadership in many low- and middle-income countries (15). Consequently, calls have been made to take into account the ways in which gender intersects with other social identities and stratifying factors to create unique experiences of marginalization and disadvantage (15). How gender and intersectionality define recruitment and retention of health workforce in Africa is yet to be fully explored.

The objective of this review is to show how gender intersects with other sociocultural determinants of health, including age, race, class, (dis)ability, education, professional hierarchy, economic security, residence, marital status, patriarchy and work grouping, to create different experiences of marginalisation and/ or privilege in the recruitment and retention of health workers in Africa. Through this review we aim to propose recommendations to policy-makers to address the challenges to the health workforce caused by intersectionality of gender.

\section{Methods}

We undertook a rapid review, which accelerates and streamlines the conventional systematic review processes in order to provide policy-makers with timely evidence for policy formulation (16). We searched PubMed in March 2020 to identify studies published in English from 1966 to 2020 that investigated the intersectionality of gender in relation to recruitment and retention of health workers in Africa. We used mainly the PubMed database for extraction of relevant publications because studies indexed in PubMed are regarded to be reliable as they underwent undergone a reasonable peer review process.

We retrieved 193 publications using the following key words. Category 1) gender, employment, health workers, Africa - 167 publications; Category 2) gender, health workforce, recruitment, Africa - 9 publications; and Category 3: gender, health workforce, retention, Africa -17 publications. The criteria for inclusion of studies were: primary research, not review articles; related to the role of gender and intersectionality in recruitment and retention of the health workforce; conducted in Africa; and quantitative or qualitative study design. Studies not published in English were excluded.

The first author independently searched and retrieved relevant publications, by screening titles of publications and the abstracts, and retrieving full texts of publications that fulfilled the inclusion criteria. The second author independently verified the publications and checked for their completeness and accuracy. Differences were resolved through discussion and consensus.

\section{Results}

Of the 193 publications found, nine (5\%) met the inclusion criteria: six of 167 studies in category 1 , one of nine publications in category 2 , and three of 17 publications in category 3 (however, one in category 3 was duplicated and so was excluded). Of the nine studies included, six were qualitative studies, two used a mixed method design and one was a cross-sectional survey. Three of the studies were conducted in South Africa, one was a multicountry study (Cambodia, Sierra Leone, Uganda and Zimbabwe), and the others were carried out in Ethiopia, Kenya, Malawi, Niger and United Republic of Tanzania. The results are shown in Table 1.

\section{Intersections of gender in recruitment}

Two studies reported on the intersection of gender in recruitment of health workers. In one of the studies, feminization of the nursing profession was documented to result in difficulties in recruiting and deploying female health workers in rural zones (17). The second study reported that the issue of gender was absent in the policy on lay health workers and that policy developers were not 


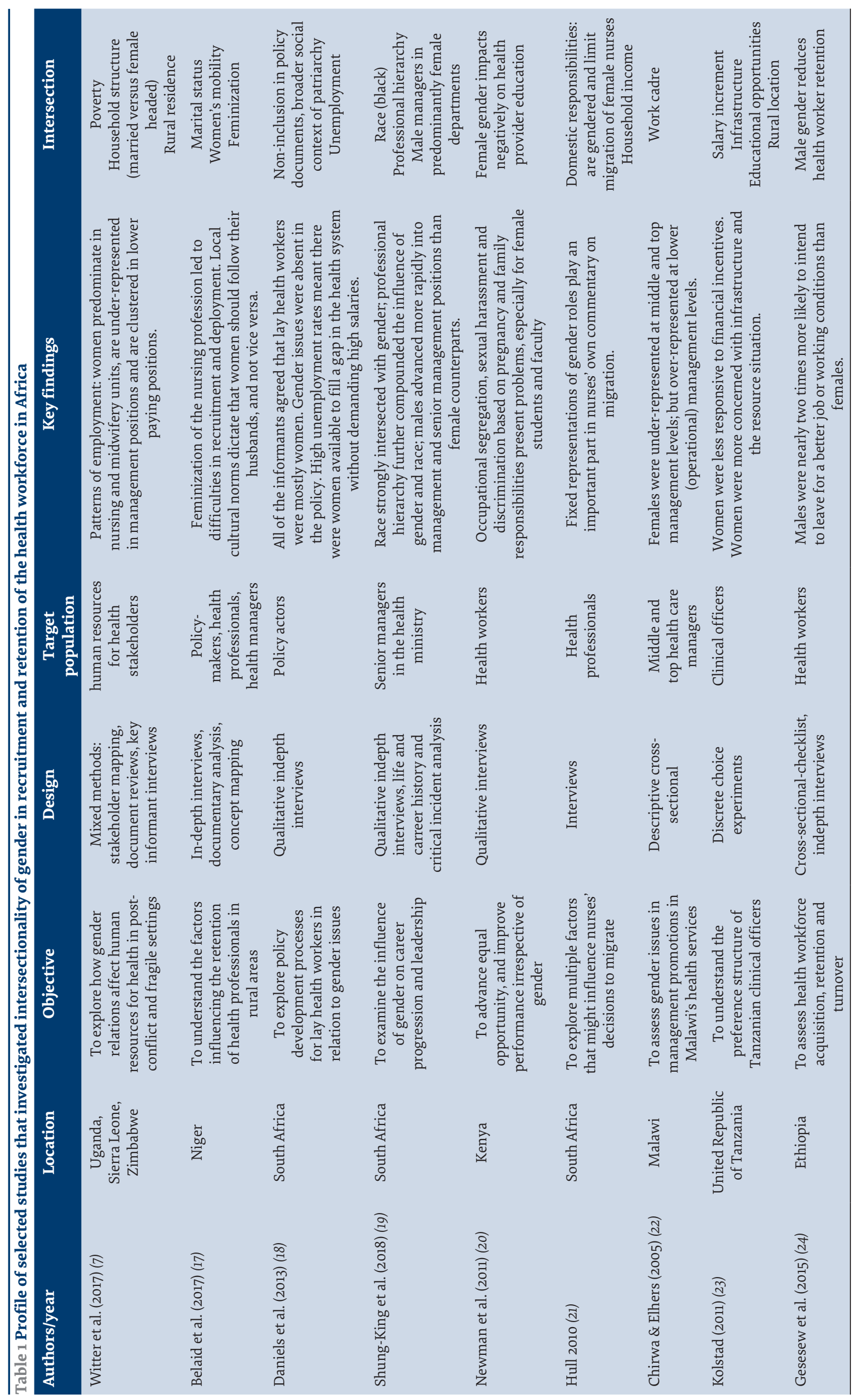


aware of gender-based problems associated with working conditions. The high unemployment rates meant women were available to fill a gap in the health system without being in a position to demand higher salaries. The social context of patriarchy also intersected with gender to affect recruitment and employment of female health workers (18).

\section{Intersections of gender in retention}

Eight studies described the effect of gender on the retention of health workers. In one of the studies, being black and the professional hierarchy within the system limited professional development (retention) of women. In addition, there were more male managers in predominantly female departments (19). Female gender was reported to have a negative effect on health provider education by one of the studies. Occupational segregation, sexual harassment and discrimination based on pregnancy and family responsibilities were problems faced by female students and faculty members in this study (20). In another study, women predominated in nursing and midwifery units but were under-represented in management positions and were clustered in lower paying positions. Gendered power relations shaped by women's household responsibilities negatively affected rural deployment of female health workers largely because of patriarchal dominance. Furthermore, women in all contexts face challenges in accessing both pre- and inservice training (7). Similarly, findings from another study showed that for married women local cultural norms dictate that women follow their husbands and not vice versa, hence affecting retention in rural areas (17).

Other studies highlighted gender as a fixed representation (main determining factor) on migration of nurses in search of better work opportunities. Female nurses were more likely to migrate than their male counterparts (21). Females were under-represented at middle and top management levels but over-represented at lower (operational) management levels (22). In exploring ways to achieve retention in rural areas, another study found that women tended to be significantly less responsive to financial incentives than men (23). In another study, males were nearly twice as likely to intend to leave for a better job or working conditions than females - i.e. less likely to be retained (odds ratio $=1.6$; 95\% confidence interval: 1.0-2.5) (24).

\section{Discussion}

The outcome of this review confirms the findings of previous reports which showed that gender and intersectionality are important social stratifying factors that intersect in dynamic and interactive ways to influence the health systems in general and human resources for health more specifically $(8,12,25)$. All the studies reviewed showed the strong influence of gender on the recruitment and retention of the health workforce in Africa. Thus, gender analysis can be used to explain the documented inequalities between male and female health workers and variations in how the health workforce is recognized, valued and supported. Differences exist at the professional level (career trajectories, pay, training and other technical resources and professional networks) and at the personal level (personal safety, stress, autonomy, self-esteem, family and other social relationships) (26-28).

One important finding in our review is the feminization of certain categories of health professions. Feminization of the nursing and midwifery profession was shown to result in difficulties in recruiting, deploying and maintaining female health workers, especially in rural areas (17). Zurn and colleagues observed that the distribution of women by occupational category is biased in favour of nursing and that women are very poorly represented in other categories, such as dentistry, medical assistant jobs, pharmacy, managerial/training jobs and medicine (4).

The predominance of females in the nursing profession is common worldwide because nursing is often labelled as the work of women. A number of previous reports have shown the very strong link between female gender and nursing and described it to be associated with the feminine nature of nurturing, caring, empathy and gentleness as opposed to masculine characteristics (29-31). According to a study in Mauritius, nursing is associated with relatively low status owing to gender and income, and is also influenced by cultural perceptions of social status, the nature of the work and sexuality (32). In Africa, where cultural perceptions of social status favour patriarchal dominance, it is not a surprise that nursing is a female-dominated occupation. In fact, men who choose to go into nursing are often portrayed as not "real" men, effeminate, homosexuals, somewhat suspicious and out to seek to benefit from some hidden advantages $(29,30,33)$. Because the nursing profession is gender segregated and influenced by cultural traditions which promote male dominance, male nurses are often treated in a special way and given privileged positions in the health care settings (32).

Our review also indicates male dominance in leadership and management positions in the health workforce $(18,19,22)$. Available statistics indicate that women make up more than $70 \%$ of the health care workforce and are the largest users of health care, yet they remain very under-represented in top management and executive leadership positions (4). A recent study noted that women's role as child bearers and gendered societal expectations, including child nurturing and other domestic responsibilities, can influence their ability to take up leadership opportunities, and their selection and appointment as leaders (35). In another study, prejudicial cultural values and gendered social roles and expectations were found to hinder the career advancement of women in health care (36).

A number of studies have shown that stereotypical male and female attributes and behaviours have led to men and women largely preferring male leaders, even when the credentials of male and female candidates are the same $(37,38)$. It has been argued that stereotypical 
female attributes, such as cooperation, modesty and emotiveness, tend to be perceived as incompatible with strong leadership, whereas stereotypical male attributes, such as assertiveness, stability, achievement orientation and independence, tend to be viewed as fundamental to leadership (39). Furthermore, women sometimes lack the desire to hold a managerial position, given that they are more committed to their families, child care and matrimonial responsibilities than to their careers, compared with their male counterparts (40).

The under-representation of women in managerial and decision-making positions may lead to less attention being given to and a poorer understanding of the problems specific to women (41). In the WHO report on gender mainstreaming for health managers, it was noted that addressing gender equality in the workplace requires more than ensuring that women and men can participate at different levels of the organization (42). It also requires ensuring that, once women are recruited and hired, they receive equitable treatment and opportunities to perform their duties to the best of their ability (42). WHO is supporting a joint inter-agency health workforce expansion and transformation programme which has gender as a core principle and seeks to use workforce plans, investments and actions to seize the opportunities to realize the dividend from providing equal opportunities to all irrespective of gender (34).

In one of the studies reviewed, it was observed that gender power relationship in the recruitment and retention of health workers is shaped by marriage (21) and cultural norms that dictate that women follow husbands and not vice-versa (17). In a study on physician retention rate and its effective factors in the Islamic Republic of Iran, it was noted that at the individual level, gender is not a primary factor in retention while marital status was, i.e. married physicians showed greater willingness to stay in their area of origin (43). Another study reported the influence of gender on career trajectories, in particular gender roles within dual-career households, with some female professionals prioritizing their male partners' careers ahead of their own (19). There is sufficient evidence that shows that it is common for women health care professionals to prioritize family demands over their careers $(44,45)$. In Africa, where sociocultural determinants of health are very pronounced, the intersection of gender will continue to exert a strong influence on the health systems. According to WHO, addressing gender norms, roles and relations enables better understanding of how sociocultural identity construction (male and female), attribution of rights and unequal power relations can affect components of the health system, including the health workforce (46).

The attempt to meet family and other social demands has led many female health workers to reject or forfeit well paid job offers or transfers to locations where their families do not live, some even opting to remain unemployed. In one of the studies we reviewed, a high rate of unemployment among female health professionals meant they were available to fill gaps without being able to ask for higher salaries (18). In a previous report of gender analysis by the WHO Commission on the Social Determinants of Health, it was noted that not only are women over-represented in caring, informal, part-time, unskilled and unpaid work, and work that is routinely not measured, but women's contributions also cover a range of activities that blur some of these conventional distinctions (26). It is widely recognized that women's lower status is often institutionalized through social, economic and political structures of the society with institutions being more inclined to marginalization of women in employment, promotion and leadership or managerial positions (46). There is need to strengthen mechanisms and initiate policies that will address the broader sociopolitical factors, power dynamics and cultural factors that are responsible for gender discrimination in recruitment and retention in the health workforce.

An important finding of one of the studies reviewed is the occupational segregation, sexual harassment, violence and discrimination against the female health workers based on certain social demands, such as family responsibility and pregnancy (20). It is reported that in Saudi Arabia, women in the medical field can achieve good success at junior levels but are exposed to some degree of discrimination at higher levels (47). In addition, because of contact with male medical staff and patients and night shifts, employment for women in the medical field is not always welcomed.

Occupational segregation and sorting of men and women into specific types of job are key contributing factors to inequality in pay with women more concentrated in low-grade and low-paying jobs, the public sector and part-time employment (48-50). In addition to discrimination against female health workers, other factors that contribute to this gender pay gap include women's dual roles in the workplace and family. For instance, a larger proportion of female health workers are likely to take parental leave than their male counterparts. Furthermore, the lack of facilities for child care in health care settings forces more women out of work than men $(48,49)$. Previous reports on gender and human resources for health have shown that gender discrimination and inequality are key barriers to entry, reentry and retention in employment systems, especially for female health workers $(5,26,51)$.

Women are reported to face a disproportionate burden of violence and discrimination across all sectors, but the female-dominated occupations such as health and social care services are at greater risk $(52,53)$. A gender analysis of the health workforce also revealed significant levels of violence experienced by women health workers who are disproportionately victimized because of gendered ideologies that subjectively sanction such violence or because of their disadvantaged position within the health workforce (26). In Afghanistan, it was reported that increased insecurity in remote areas affects the mobility of health professionals, especially females (54). In order to increase the retention of female health workers in 
rural and remote areas, Afghanistan started to provide opportunities for male family members and spouses to deploy to the same health facilities (54).

According to $\mathrm{WHO}$, female health workers face harassment and violence from three sources-male colleagues, male patients and the wider community, including visitors to facilities or men in the community if they are outreach workers (55). In addition, the stigma in reporting cases in the health profession has created a misperception that harassment cases are rare (55). In a quantitative review of workplace violence among more than 150000 nurses mostly females, overall violence exposure rates were $36.4 \%$ for physical violence, $66.9 \%$ for nonphysical violence, $39.7 \%$ for bullying and $25.0 \%$ for sexual harassment, with $32.7 \%$ of nurses reporting having been physically injured in an assault (56).

In Rwanda, it was reported that about $39 \%$ of health workers faced at least one form of workplace violence, such as verbal abuse, bullying and sexual harassment, in the 12 months before the study, with female health workers being disproportionately affected (57). Furthermore, women health and social care workers working in conflict-affected regions or remote settings are highly vulnerable to violence and sexual harassment (7). To address sexual harassment and discrimination, it has been suggested that policies and mechanisms be established that promote equal opportunity, nondiscrimination, gender equality and respect for human rights, all of which should be core health professional values and competencies (15).

In conclusion, our review highlights the importance of considering gender analysis in the development of policies and programmes for human resources for health in Africa. There are however a number of limitations to this study. First, some of the studies/papers included are old and so the situation may have changed. Second, we limited our search to the PubMed, and so some studies indexed in other important databases may have been missed. Third, only studies published in English were included and thus some relevant studies in French, Portuguese and Arabic, could not be assessed. In spite of these limitations, the study highlights some vital issues needed to address intersectionality of gender in African setting. WHO identified the main urgent challenges to human resources for health in Africa including: weak leadership and governance capacity for human resources for health; weak training capacity; inadequate utilization, retention and performance of available health workers; insufficient information and evidence on gender intersectionality; weak regulatory capacity; uncoordinated partnerships; and weak policy dialogue (2). To improve human resources for health in Africa, it is imperative for policymakers to develop affirmative action policies for gender equality. A number of recommendations which can help develop such policies include: (i): commissioning more studies on intersectionality of gender in human resources for health to provide local context-specific evidence for policy-making; (ii) engaging stakeholders and convening a citizens' panel to deliberate on how to address some of the key issues, such as social, cultural, economic and patriarchal factors, that influence intersectionality of gender in human resources for health; and (iii) applying gender sensitivity and gender equity in policy development on human resources for health. Funding: None

Competing interests: None declared.

\section{Intersectionnalité des questions de parité homme-femme en matière de recrutement et de fidélisation des personnels de santé en Afrique : une analyse rapide}

\section{Résumé}

Contexte : Malgré l'importance des questions de parité homme-femme et de l'intersectionnalité dans l'élaboration de politiques liées aux ressources humaines dans le domaine de la santé, ces aspects n'ont pas été dûment pris en compte dans le recrutement et la fidélisation des personnels de santé en Afrique.

Objectifs: L'objectif de la présente analyse était de montrer comment les questions de parité homme-femme se recoupent avec d'autres déterminants socioculturels de la santé pour créer des expériences différentes eu égard à la marginalisation et/ou au privilège dans le processus de recrutement ou de fidélisation des ressources humaines dans le domaine de la santé en Afrique.

Méthodes: Il s'agit d'une analyse rapide des études qui ont examiné l'intersectionnalité des questions de parité homme-femme en relation avec le recrutement et la fidélisation des personnels de santé en Afrique. Une recherche dans PubMed a été effectuée en avril 2020 pour identifier les études éligibles. Les termes de recherche utilisés comprenaient: questions de parité homme-femme, emploi, agents de santé, personnels de santé, recrutement, fidélisation. Les critères d'inclusion des études étaient les suivants : recherche primaire ; liée au rôle des questions de parité homme-femme et de l'intersectionnalité dans le recrutement et la fidélisation du personnel de santé ; menée en Afrique ; plan d'étude quantitative ou qualitative ; et publiée en anglais.

Résultats: Sur les 193 publications trouvées, neuf répondaient aux critères d'inclusion de l'étude et ont été sélectionnées. La féminisation de la profession infirmière et obstétricale entraîne des difficultés en matière de recrutement et de déploiement des personnels de santé féminins. Une dominance masculine des postes 
d'encadrement a été rapportée. La relation de pouvoir entre les hommes et les femmes dans le recrutement et la fidélisation des personnels de santé est déterminée par le mariage et les normes culturelles. La ségrégation professionnelle, le harcèlement sexuel et la discrimination à l'égard des agents de santé féminins ont été signalés.

Conclusion: La présente étude souligne l'importance de la prise en considération de l'analyse des questions de parité homme-femme dans l'élaboration des politiques et des programmes relatifs aux ressources humaines dans le domaine de la santé en Afrique.

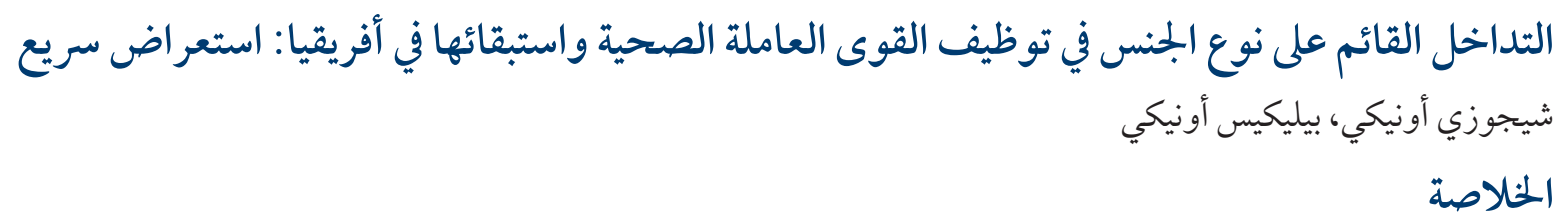

الخلفية: على الرغم من أهمية نوع الجنس والتداخل في رسم السياسات المعنية بالموارد البشرية الصحية، لم تحظَ هذه المسائل بالا هتهام الكافي في توظيف القوى العاملة الصحية واستبقائها في أفريقيا.

الأهداف: هدف هذا الاستعر اض إلى بيان كيفية تداخل نوع الجنس مع المحددات الاجتماعية الثقافية الأخرى للصححة، لتوضيح تجارب إب ختتلفة من

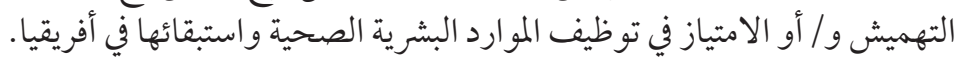

طرق البحث: كان هذا استعراضًا سريعًا لدراسات بحثت في التداخل القائم على نوع الجنس من حيث تون توظيف العاملين الصحيين واستبقائهم

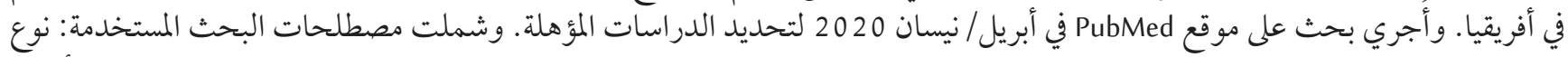

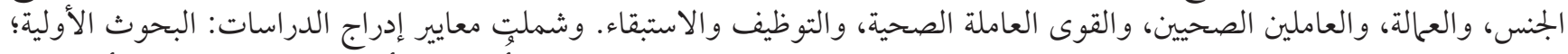

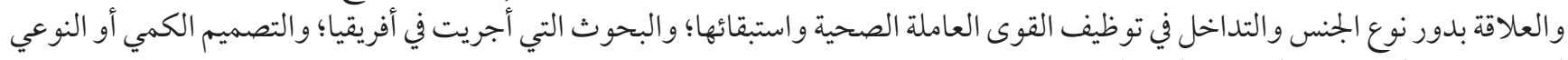
للدر اسات؛ و الدراسات المنشورة باللغة الإنجليزية.

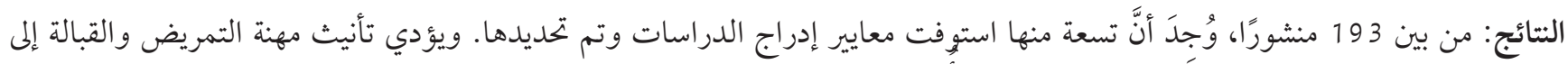

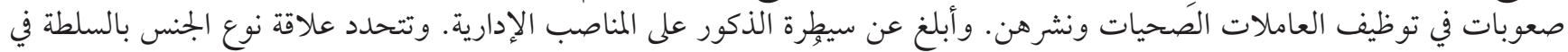

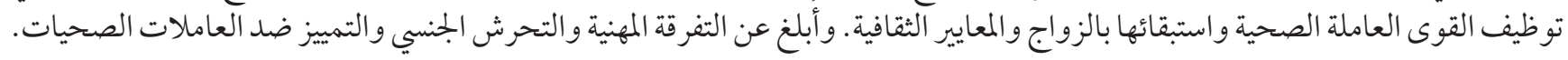
الاستنتاج: يسلط هذا الاستعراض الضوء على أهمية النظر في التحليل الجنساني عند وضع السياسات والبرامج المتعلقة بالموارد البشرية الصحية في أفريقيا.

\section{References}

1. World health statistics 2018: monitoring health for the SDGs, sustainable development goals. Geneva: World Health Organization; 2018 (https://apps.who.int/iris/handle/10665/272596, accessed 27 January 2021).

2. Road map for scaling up the human resources for health for improved health service delivery in the African Region, $2012-2025$. Brazzaville: World Health Organization, Regional Office for Africa; 2014 (https://www.afro.who.int/sites/default/files/2017-06/ road-map-hr.pdf, accessed 27 January 2021).

3. World health report 2006. Working together for health. Geneva: World Health Organization; 2006 (https://www.who.int/workforcealliance/knowledge/resources/whreport_2006/en/, accessed 27 January 2021).

4. Zurn P, Dal Poz MR, Stilwell B, Adams A. Imbalance in the health workforce. Hum Resour Health. 2004;2(1):13. https://doi. org/10.1186/1478-4491-2-13

5. Newman CJ. Time to address gender discrimination and inequality in the health workforce. Hum Resour Health. 2014;12(1):25. https://doi.org/10.1186/1478-4491-12-25

6. Reichenbach L, editor. Exploring the gender dimensions of the global health workforce. Cambridge: Harvard University; 2007.

7. Witter S, Namakula J, Wurie H, Chirwa Y, So S, Vong S, et al. The gendered health workforce: mixed methods analysis from four fragile and post-conflict contexts. Health Policy Plan. 2017;32(suppl 5):v52-62. https://doi.org/10.1093/heapol/czx102

8. Morgan R, Ayiasi RM, Barman D, Buzuzi S, Ssemugabo C, Ezumah N, et al. Gendered health systems: evidence from low- and middle-income countries. Health Res Policy Syst. 2018;16(1):58. https://doi.org/10.1186/s12961-018-0338-5

9. Gender definition. Gender, equity and human rights. Geneva: World Health Organization; 2021(https://www.who.int/gender-equity-rights/understanding/gender-definition/en, accessed 27 January 2021).

10. Hankivsky O. Women's health, men's health, and gender and health: implications of intersectionality. Soc Sci Med. 2012;74(11):1712-20. https://doi.org/10.1016/j.socscimed.2011.11.029 
11. Tolhurst R, Leach B, Price J, Robinson J, Ettore E, Scott-Samuel A, et al. . Intersectionality and gender mainstreaming in international health: using a feminist participatory action research process to analyse voices and debates from the global south and north. Soc Sci Med. 2012;74(11):1825-32. https://doi.org/10.1016/j.socscimed.2011.08.025

12. Bowleg L. The problem with the phrase women and minorities: intersectionality-an important theoretical framework for public health. Am J Public Health. 2012;102(7):1267-73. https://doi.org/10.2105/AJPH.2012.300750

13. Heard E, Fitzgerald L, Wigginton B, Mutch A. Applying intersectionality theory in health promotion research and practice. Health Promot Int. 2020;35(4):866-76. https://doi.org:10.1093/heapro/dazo80

14. Zeinali Z, Muraya K, Govender V, Molyneux S, Morgan R. Intersectionality and global health leadership: parity is not enough. Hum Resour Health. 2019;17(1):29. https://doi.org:10.1186/s12960-019-0367-3

15. Global strategy on human resources for health: workforce 2030: Geneva: World Health Organization; 2016 (https://apps.who.int/ iris/bitstream/handle/10665/250368/9789241511131-eng.pdf?sequence=1, accessed 27 January 2021).

16. Tricco AC, Langlois EV, Straus SE, editors. Rapid reviews to strengthen health policy and systems: a practical guide. Geneva: World Health Organization; 2017 (https://www.who.int/alliance-hpsr/resources/publications/rapid-review-guide/en/, accessed 27 January 2021).

17. Belaid L, Dagenais C, Moha M, Ridde V. Understanding the factors affecting the attraction and retention of health professionals in rural and remote areas : a mixed-method study in Niger. Hum Resour Health. 2017;15:60. https://doi.org:10.1186/s12960-0170227-y

18. Daniels K, Clarke M, Ringsberg KC. Developing lay health worker policy in South Africa : a qualitative study. Health Res Policy Syst. 2012;10(1):8. https://doi.org:10.1186/1478-4505-10-8

19. Shung-King M, Gilson L, Mbachu C, Molyneux S, Muraya KW, Uguru N, et al.. Leadership experiences and practices of South African health managers: what is the influence of gender? qualitative, exploratory study. Int J Equity Health. 2018;17(1):148. https://doi.org:10.1186/s12939-018-0859-0

20. Newman C, Kimeu A, Shamblin L, Penders C, McQuide P, Bwonya J. Making non-discrimination and equal opportunity a reality in Kenya's health provider education system: results of a gender analysis. World Health Popul. 2011;13(2):23-33. https://doi. org:10.12927/whp.2011.22668

21. Hull E. International migration, "domestic struggles" and status aspiration among nurses in South Africa. J South Afr Stud. 2010;36(4):851-67. https://doi.org:10.1080/03057070.2010.527641

22. Chirwa ML, Elhers VJ. Gender issues in management promotions in Malawi's health services. Curationis. 2005;28(5):4-14.

23. Kolstad JR. How to make rural jobs more attractive to health workers. Findings from a discrete choice experiment in Tanzania. Health Care Women Int. 2011;20(2):196-211. https://doi.org:10.1002/hec.1581

24. Gesesew HA, Tebeje B, Alemseged F, Beyene W. Health workforce acquisition, retention and turnover in Southwest Ethiopian Health Institutions. Ethiop J Health Sci. 2016;26(4):331-40. https://doi.org:10.4314/ejhs.v26i4.5

25. Hankivsky O, Grace D, Hunting G, Giesbrecht M, Fridkin A, Rudrum S, et al. An intersectionality-based policy analysis framework: critical reflections on a methodology for advancing equity. Int J Equity Health. 2014;13:119. https://doi.org:10.1186/s12939014-0119-x

26. George AS. Human resources for health: a gender analysis [internet]. Background to the Women and Gender Equity Knowledge Networks; 2007. (https://www.who.int/social_determinants/resources/human_resources_for_health_wgkn_2007.pdf, accessed 27 January 2021).

27. Theobald S, Morgan R, Hawkins K, Africali S, George A, Molyneux S. The importance of gender analysis in research for health systems strengthening. Health Policy Plan. 2017;32(suppl 5):v1-3. https://doi.org:10.1093/heapol/czx163

28. Morgan R, George A, Africali S, Hawkins K, Molyneux S, Theobald S. How to do (or not to do)... gender analysis in health systems research. Health Policy Plan. 2016;31(8):1069-78. https://doi.org/10.1093/heapol/czw037

29. Evans J. Cautious caregivers: gender stereotypes and the sexualization of men nurses' touch. J Adv Nurs. 2002;40(4):441-8. https://doi.org/10.1046/j.1365-2648.2002.02392.x

30. Evans J. Men in nursing: issues of gender segregation and hidden advantage. J Adv Nurs. 1997;26: 226-31. https://doi.org/10.1046/ j.1365-2648.1997.1997026226.x

31. Meadus RJ. Men in nursing: Barriers to recruitment. Nurs Forum. 2000;35(3):5-12. https://doi.org/10.1111/j.1744-6198.2000. tboog98.x

32. Hollup O. The impact of gender, culture, and sexuality on Mauritian nursing: Nursing as a non-gendered occupational identity or masculine field? Qualitative study. Int J Nurs Stud. 2014;51(5):752-60. https://doi.org/10.1016/j.ijnurstu.2013.09.013

33. Williams C. Hidden advantages for men in nursing. Nurs Admin Quart. 1995;19(2):63-70. https://doi.org/10.1097/00006216199501920-00012

34. Boniol M, McIsaac M, Xu L, Wuliji T, Diallo K, Campbell J. Gender equity in the health workforce: analysis of 104 countries. Working paper 1. Geneva: World Health Organization; 2019 (https://www.who.int/hrh/resources/gender_equity-health_workforce_analysis/en/, accessed 27 January 2021). 
35. Muraya KW, Govender V, Mbachu C, Uguru NP, Molyneux S. "Gender is not even a side issue...it's a non-issue": career trajectories and experiences from the perspective of male and female healthcare managers in Kenya. Health Policy Plan. 2019;34(4):24956. https://doi.org/10.1093/heapol/czzo19

36. Tlaiss HA. Women in healthcare: barriers and enablers from a developing country perspective. Int J Health Pol Manag. 2013;1:2333. https://doi.org/10.15171/ijhpm.2013.0

37. Lantz PM. Gender and leadership in healthcare administration: 21st century progress and challenges. J Healthc Manag. 2008;53(5):291-301; discussion 302-3.

38. Carnes M. Bland C. Viewpoint: a challenge to academic health centers and the national institutes of health to prevent unintended gender bias in the selection of clinical and translational science award leaders. Acad Medicine. 2007;82(2):202-06. https://doi. org/10.1097/ACM.obo13e31802d939f

39. Eagly AH, Wood W. Explaining sex differences in social behavior: a meta-analytic review of the social psychological literature. Psychol Bull. 2001;100:309-30. https://doi.org/10.1177/0146167291173011

40. Powell GN, Mainero LM. Cross-currents in the river of time: conceptualizing the complexities in women's careers. J Manag. 1992;18:215-37. https://doi.org/10.1177/014920639201800202

41. Standing H, Baume E. Equity, equal opportunities, gender and organization performance. Paper presented for the Workshop on Global Health Workforce Strategy: Annecy, France, 9-12 December 2000. Geneva: World Health Organization; 2001 (https:// www.who.int/hrh/documents/en/Equity.pdf, accessed 27 January 2021).

42. Gender mainstreaming for health managers: a practical approach. Participant's guide. Geneva: World Health Organization; 2011 (https://www.who.int/gender-equity-rights/knowledge/health_managers_guide/en/, accessed 27 January 2021).

43. Ehsani-Chimeh E, Majdzadeh R, Delavari S, Gharebelagh MN, Rezaei S, Rad EH. Physicians' retention rate and its effective factors in the Islamic Republic of Iran. East Mediterr Health J. 2018;24(9):830-7. https://doi.org/10.26719/2018.24.9.830

44. McDonagh KJ. Secrets of the labyrinth: insights into career advancement for women. Nurse Leader. 2010;8:41-43. https://doi. org/10.1016/j.mnl.2010.05.010

45. Tlaiss HA. Women in healthcare: barriers and enablers from a developing country perspective. Int J Health Policy Manag. 2013;1(1):23-33. https://doi.org/10.15171/ijhpm.2013.05

46. Gender mainstreaming for health managers: a practical approach. Facilitator's guide. Geneva: World Health Organization; 2011 (https://www.who.int/gender-equity-rights/knowledge/health_managers_guide/en/, accessed 27 January 2021).

47. Mobaraki AEH, Söderfeldt B. Gender inequity in Saudi Arabia and its role in public health. East Mediterr Health J. 2010;16(1):1138.

48. Working paper on gender \& equity in the health and social care workforce. Consultative draft report. Geneva: World Health Organization; 2018 [internet]. (https://www.who.int/hrh/news/2018/GEHworking-paper-ZeroDraft.pdf, accessed 27 January 2021).

49. Rubery J, Grimshaw D, Figueiredo H. How to close the gender pay gap in Europe: towards the gender mainstreaming of pay policy. Ind Relation J. 2005; 36(3):184-213.

50. Equality at work: the continuing challenge. Global report under the follow-up to the ILO Declaration on Fundamental Principles and Rights at Work. Report of the Director-General. Geneva: International Labour Organization; 2011 (https://www.ilo.org/declaration/info/publications/eliminationofdiscrimination/WCMS_166583/lang--en/index.htm, accessed 27 January 2021).

51. Standing H. Gender-a missing dimension in human resource policy and planning for health reforms. Human Res Health Development J. 2000;4:27-42.

52. Violence: a worldwide epidemic [factsheet]. Geneva: International Council of Nurses; 2005.

53. Cooper C, Swanson N. Workplace violence in the health sector [internet]. 2002 (http://www.who.int/violence_injury_prevention/ violence/activities/workplace/WVstateart.pdf., accessed 27 January 2021).

54. Safi N, Naeem A, Khalil M, Anwari P, Gedik G. Addressing health workforce shortages and maldistribution in Afghanistan. East Mediterr Health J. 2018;24(9):951-8. https://doi.org/10.26719/2018.24.9.951

55. Delivered by women, led by men: a gender and equity analysis of the global health and social workforce. Geneva: World Health Organization; 2019 (https://www.who.int/hrh/resources/health-observer24/en/, accessed 27 January 2021).

56. Spector PE, Zhou ZE, Che XX. Nurse exposure to physical and nonphysical violence, bullying, and sexual harassment: a quantitative review. Int J Nurs Stud. 2014;51(1):72-84. https://doi.org/10.1016/j.ijnurstu.2013.01.010

57. Newman CJ, de Vries DH, d'Arc Kanakuze J, Ngendahimana G. Workplace violence and gender discrimination in Rwanda's health workforce: Increasing safety and gender equality. Hum Resour Health. 2011;9:19. https://doi.org/10.1186/1478-4491-9-19 